\title{
Ocular Infection by Multidrug-Resistant Acinetobacter baumannii Causes Eyeball Evisceration-A Case Report
}

\section{Guilherme Barreto de Oliveira Ribeiro ${ }^{1}$, Marcela de Almeida Costa Marques ${ }^{2}$, Jean Phellipe Marques do Nascimento ${ }^{3}$, Eliege Maria dos Santos, Roseana de Almeida Cunha Bastos ${ }^{5}$ and Eurípedes Alves da Silva Filho ${ }^{3 *}$}

${ }^{1}$ Oculare-Clinic of Advanced Ophthalmology, Maceió-AL, Brazil

${ }^{2}$ Hélia Mendes Laboratory, Maceió-AL, Brazil

${ }^{3}$ Federal University of Alagoas, Institute Biological Sciences and Health,

Laboratory of Genetic and Applied Microbiology, Maceió-AL, Brazil

${ }^{4}$ Professor Alberto Antunes University Hospital, Maceió-AL, Brazil

${ }^{5}$ Central Laboratory of Alagoas - LACEN, Maceió-AL, Brazil

*Corresponding author

\begin{tabular}{|c|c|}
\hline & A B S T R A C T \\
\hline & \multirow{8}{*}{$\begin{array}{l}\text { Acinetobacter baumannii is a bacterial species capable of provoking several clinical } \\
\text { manifestations and possessing several mechanisms of antimicrobial resistance, besides } \\
\text { adapting to adverse situations, thus enabling its permanence in health centers. The broad } \\
\text { spectrum of infections caused by this species also includes eye infections, which may lead } \\
\text { to a serious clinical outcome depending on the circumstances. Endophthalmitis is one of } \\
\text { the most serious complications amongst ophthalmological infections, which can be caused } \\
\text { by fungi and bacteria. Although not very frequent, cases of endophthalmitis caused by A. } \\
\text { baumanni have been described in the literature, with differentiated clinical outcomes being } \\
\text { observed. Our objective is to report a case of postoperative endophthalmitis caused by } \\
\text { multi-drug resistant } A \text {. baumannii, identified as from vitreous humor collection and an } \\
\text { antimicrobial susceptibility profile confirmed by automated testing. The worsened } \\
\text { infection and failure to treat the microorganism via antibiotic therapy resulted in ocular } \\
\text { globe evisceration of an immunocompetent } 70 \text {-year-old male patient with no related } \\
\text { clinical history on the } 17 \text { th day after a surgery for cataract removal by phacoemulsification } \\
\text { with implantation of intraocular lens (IOL). }\end{array}$} \\
\hline & \\
\hline Acinetobacter & \\
\hline $\begin{array}{l}\text { baumannul, } \\
\text { Endophthalmitis, }\end{array}$ & \\
\hline $\begin{array}{l}\text { Ocular infection, } \\
\text { Ocular evisceration. }\end{array}$ & \\
\hline Article Info & \\
\hline $\begin{array}{l}\text { Accepted: } \\
\text { 15 March } 2 \\
\text { Available } \\
10 \text { April } 20\end{array}$ & \\
\hline & \\
\hline
\end{tabular}

\section{Introduction}

Acinetobacter baumannii has been worldwide recognized as a pathogen causing serious infections in humans, leading to great concern about its presence in hospital environments (Kamble, 2015). Hospitalized patients who have undergone invasive procedures or even in immunosuppressive conditions can easily be affected by this microorganism
(Patwardhan et al., 2008). Although not very common, ocular infections, particularly endophthalmitis, caused by the Acinetobacter genus species (including the A. baumannii), have been frequently observed in the literature in recent years (Talreja et al., 2014a). The aim of this report is to describe a case of eyeball evisceration associated with $A$. 
baumannii infection with an antimicrobial resistance profile.

\section{Case Report}

A 70-year-old retired immunocompetent male patient from the community, with no correlated clinical history, was submitted to a cataract removal surgery by phacoemulsification and intraocular lens (IOL) implantation at the surgical center of an ophthalmologic clinic. On postoperative day (POD) 1 , the patient had a $+++/ 4+$ corneal edema, formed anterior chamber (FAC), regular pupil, topical IOL, small hemorrhage area in the inferior iris and intraocular pressure (IOP) of $12 \mathrm{mmHg}$. Since leaving the surgical center, the patient had already been using the standard prescription with Vigadexa® (Moxifloxacin Hydrochloride 5 $\mathrm{mg} / \mathrm{ml}$ and Dexamethasone Disodium Phosphate $0.1 \mathrm{mg}$ ) every 4 hours, as well as Nevanac $($ (Nepafenac $1 \mathrm{mg} / \mathrm{ml}$ ) every12 hours. On day 5(POD), there was improvement of corneal ++ / 4+ edema, but there was an increase in intraocular pressure $(20 \mathrm{mmHg})$ with a secondary microcystic edema. Azorga ${ }^{\circledR}$ (Brinzolamide $10 \mathrm{mg} / \mathrm{ml}$ and Timolol Maleate $6.8 \mathrm{mg} / \mathrm{ml}$ ) every 12 hours was then added. On day 9(POD), the patient returned reporting eye pain, redness and visual blurring. The examination showed $24 \mathrm{mmHg}$ IOP, $1 \mathrm{~mm}$ hypopyon, besides an inflammatory irian membrane. When questioned about the correct use of eye drops, he reported having mistakenly applied an oral drops medication (Dipirone Drops).

Surgical removal of the inflammatory membrane and washing the anterior chamber with Vancomycin $(50 \mathrm{mg} / \mathrm{ml})$ and Amicacin $(50 \mathrm{mg} / \mathrm{ml})$ were indicated and performed on the same day. On day 11(POD), the patient evolved to worsening of the condition, with reappearance of hypopyon, ocular hypertension and inflammatory membrane, despite the previous treatment. A B-mode ultrasound scanning was performed, revealing vitreous condensations suggestive of infectious endophthalmitis. On the same day, a posterior vitrectomy was performed with vitreous humor for culture and antibiogram being collected, and an intra-vitreous injection of Vancomycin $(1 \mathrm{mg} / 0.1 \mathrm{ml})$ and Amicacin $(0.4 \mathrm{mg} / 0.1 \mathrm{ml})$ was given.

Ciprofloxacin 250mg every 12 hours was prescribed postoperatively. After 48 hours, the culture of the vitreous humor revealed the presence of the antibiotic resistant $A$. baumannii bacteria through automation identification in VITEK 2 compact AST 281, confirmed by molecular biology (Fig. 1) through species-specific primers that amplify a fragment of 208 base pairs of the internal transcribed spacer (ITS) of A. baumannii ribosomal DNA, by the DNA polymerase chain reaction (PCR) (Chen et al., 2007). On day 15(POD), the patient developed lancinating pain, worsening of the ocular condition, loss of light perception, and no response to previous treatments. An ocular evisceration was then indicated and performed on day 17 (POD), with the implant of an acrylic prosthesis.

\section{Results and Discussion}

Acinetobacter spp are immobile Gramnegative coccobacilli, belonging to the group of glucose-non fermenting bacteria found in water, soil and animals. The genus has about 31 different species, some of which are commonly found as colonizers of human skin, having the A. baumannii undoubtedly as the most prominent species for having become an opportunistic pathogen responsible for a broad spectrum of nosocomial infections at a global level, including bacteremia, meningitis, urinary and respiratory infections (Dijkshoorn et al., 2007). 
Table.1 Antibiotic-susceptibility patterns of A. baumannii isolate from endophthalmitis after phacoemulsification surgery with intraocular lens implantation

\begin{tabular}{lc}
\hline \multicolumn{1}{c}{ Antibiotics } & Susceptibility result ${ }^{\mathrm{a}}$ \\
\cline { 2 - 2 } Ampicilin & $\mathrm{MIC}\left(\mu \mathrm{g} \cdot \mathrm{mL}^{-1}\right)$ \\
\hline Ampicilin/Sulbactam & $\mathrm{R}(\geq 32)$ \\
Cefuroxime & $\mathrm{S}(\leq 2)$ \\
CefuroximeAxetil & $\mathrm{R}(\geq 64)$ \\
Cefoxitin & $\mathrm{R}(\geq 64)$ \\
Ceftazidime & $\mathrm{R}(\geq 64)$ \\
Ceftriaxone & $\mathrm{R}(\geq 64)$ \\
Cefepime & $\mathrm{R}(\geq 64)$ \\
Imipenem & $\mathrm{R}(\geq 64)$ \\
Meropenem & $\mathrm{S}(0,5)$ \\
Amicacin & $\mathrm{S}(0,5)$ \\
Gentamicin & $\mathrm{S}(16)$ \\
Ciprofloxacin & $\mathrm{R}(\geq 16)$ \\
Tigecycline & $\mathrm{R}(\geq 4)$ \\
Colistin & $\mathrm{R}(\geq 8)$ \\
\hline
\end{tabular}

${ }^{\mathrm{a}} \mathrm{S}$, susceptible; R, resistant

Fig.1 PCR products of A. Baumannii amplified by specie-specific primers resolved by agarose gel electrophoresis/ (lane A) 100bp DNA size ladders; (lane B) A. baumannii positive control/CCBH23163/Oswaldo Cruz Foundation/FIOCRUZ (lane C) 208 bp amplified fragment of A.baumanni endophthalmitis isolate (lane D) negative control

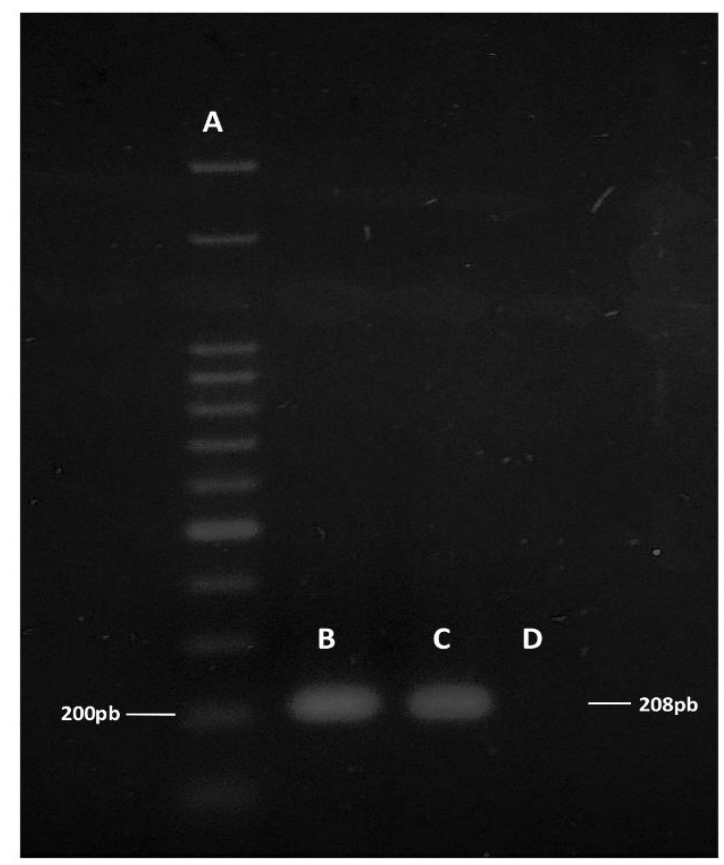


Ocular infections caused by bacteria may occur and the increasing use of intravitreal injections in the treatment of retinal diseases may be a major factor in the incidence of such infections (Sadaka et al., 2012). Acinetobacter spp have been recently related to serious cases of postoperative ophthalmological infections described in the literature (Roy et al., 2013; Broniek et al., 2014). Gopal et al., (2000) described a case of endophthalmitis after cataract surgery with intraocular lens implantation caused by Acinetobacter lwoffii; years later, the same author described a series of endophthalmitis cases, where the etiologic agent involved was the Acinetobacter calcoaceticus (Gopal et al., 2003). The clinical outcomes observed inpatients in the described cases varied, ranging from retinal detachments and proliferative vitreoretinopathy, as well as evisceration of the ocular globe (Gopal et al., 2003). Endophthalmitis caused by $A$. lwoffi and $A$. baumannii occurring after cataract surgery was also described by Roy et al., (2015) and Bitirgen et al., (2013), respectively. The involvement of $A$. baumanniiin cases of endogenous endophthalmitis and corneal post-transplant endophthalmitis have been reported also by Chen et al., (2008).

A clinical profile and antibiotic susceptibility patterns of $A$. baumannii isolates involved in post-trauma endophthalmitis and cataract surgery have also been more frequently reported in the literature probably due to the increasing resistance observed in Acinetobacter spp (Roy et al., 2013; Talreja et al., 2014b). Favorable clinical outcomes with visual acuity recovery of patients under treatment with antibiotic therapy in endophthalmitis occurrences by Acinetobacter spp. after phacoemulsification surgery with intraocular lens implantation has been demonstrated (Roy et al., 2015; Bitirgen et $a l ., 2013)$. On the other hand, endophthalmitis caused by multidrug-resistant $A$. baumannii has been reported (Chen et al., 2008). In this report, the isolate described presented sensitivity to carbapenems, but was resistant to other classes of antibiotics such as quinolone (ciprofloxacine), penicillin (ampicillin), cephalosporine (ceftriaxone, ceftazidime, cefepime, cefoxitine, cefuroxime, cefuroximeaxetil, aminoglycoside (gentamicine), and glycylcycline (tigecycline) confirmed by automated tests (Table 1).

It is indisputable that the great relevance of $A$. baumannii as one of the main pathogens of nosocomial infections is due to its great power in acquiring resistance to several antibiotics in use, limiting the therapeutic possibilities. The resistance of A. baumannii to carbapenems has been increasingly observed (Nath and Barkataki, 2016; Rivera et al., 2016; Zalts et al., 2016), and in this scenario, there are few therapeutic options to combat Acinetobacter species as the use of colistin, however, resistance has been documented (Gomes et al., 2016).

In conclusion, in this report we describe a bacterial isolate confirmed as A. baumannii by molecular techniques, such as the causal agent of bacterial endophthalmitis after phacoemulsification surgery with intraocular lens implantation. The patient did not respond satisfactorily to the antibiotic therapy used, with evolution of the infectious condition. Since the bacterial isolate showed antibiotic multidrug-resistance, the patient was referred for ocular evisceration surgery.

\section{References}

Bitirgen, G., Ozkagnici, A., Kerimoglu, H. and Kamis, U. 2013. Acute post operative endophthalmitis with an unusual infective agent: Acinetobacter baumannii. J. Cataract Refract. Surg., 
Volume, 39, pp 143-144.

Broniek, G., Langwińska-Wośko, E., Szaflik, J. and Wróblewska, M. 2014. Acinetobacter junii as anaetiological agent of corneal ulcer. Infect., Volume 42, Issue 6, pp 1051-1053.

Chen, Kuan-Jen., Hou, Chiun-Ho., Sun, Ming-Hui., Lai, Chi-Chun., Sun, ChiChin. andHsiao, Ching-Hsi. 2008. Endophthalmitis Caused by Acinetobacter baumannii: Report of Two Cases. J. Clin. Microbiol., Volume 46, Number 03, pp. 1148-1150.

Chen, T.L., Siu, L.K., Wu, R.C., Shaio, M.F., Huang, L.Y., Fung, C.P., Lee, C.M. and Cho, W.L. 2007. Comparison of onetube multiplex PCR, automated ribotyping and intergenicspacer (ITS) sequencing for rapid identification of Acinetobacter baumannii. Clin. Microbiol. Infect., 13(8): 801-806.

Dijkshoorn, L., Nemec, A. and Seifert, H. 2007. An increasing threat in hospitals: multidrug-resistant Acinetobacter baumannii. Nat Rev. Microbiol., 5: 939-95.

Gomes, D.B.C., Genteluci, G.L., Carvalho, K.R., Medeiros, L.M., Almeida, V.C., Castro, E.A.R. and Villas-Boas, M.H.S. 2016. Multidrug Resistant Acinetobacer baumanni: the occurrence of polymyxin resistance in Rio de Janeiro. Vigil. sanit. Debate., 4(3): 28-34.

Gopal, L., Ramaswamy, A.A., Madhavan, H.N., Battu, R.R., Sharma, T., Shanmugam, M.P., Bhende, P.S., Bhende, M., Ratra, D., Shetty, N.S. and Rao, N.K. 2003. Endophthalmitis Caused by Acinetobactercal coaceticus. A Profile. Indian J. Ophthalmol., Volume 51, Number 04, pp. 335-340.

Gopal, L., Ramaswamy, A.A., Madhavan, H.N., Saswade, M. andBattu, R.R. 2000. Postoperative Endophthalmitis Caused by Sequestered Acinetobactercalcoaceticus. Am. J.
Ophthalmol., 129: 388-390.

Harekrishna Nathand Dipa Barkataki. 2016. Study of Acinetobacter Isolates from Clinical Specimens in Tertiary Care Hospital and their Antimicrobial Susceptibility Pattern. Int. J. Curr. Microbiol. App. Sci., 5(10): 842-848.

Martins, A.F. and Barth, A.L. 2013. Multidrug-resistant Acinetobacter - a challenge for public health. Scientia Medica., 23(1): 56-62.

Patwardhan, R.B., P.K. Dhakephalkar, K.B. Niphadkar, B.A. Chopade. 2008. A study on nosocomial pathogens in ICU with special reference to multi resistant Acinetobacter baumannii harbouring multiple plasmids, Indian J. Med. Res., pp 178-187.

RahulKamble. 2015. Acinetobacter species in Health Care setting: Clinical significance and Antimicrobial sensitivity. Int. J. Curr. Microbiol. App. Sci., 4(4): 861-869.

Rivera, G., Bulnes, J., Castillo, C., Alenjo, M.J., Garcia, P. and Labarca, J. 2016. Extensively drug-resistant Acinetobacter baumannii isolated in a university hospital: Role ofinterhospital transmission. J. Infect. Dev. Ctries., 10(1): 096-099.

Roy, R., Das, D., Kumar, S. and Mukherjee, A. 2015. Postcataract Surgery Endophthalmitis Caused by Acinetobacter lwoffii. Middle East Afr. J. Ophthalmol., Volume 22, Number 02, pp 253-254.

Roy, R., Panigrahi, P., Malathi, J., Pal, S.S., Nandi, K., Patil, A., Nigam, E. and Arora, V. 2013. Endophthalmitis caused by Acinetobacter baumanni: a case series. Eye, 27: 450-452.

Sadaka, A., Durand, M.L. and Gilmore, M.S. 2012. Bacterial endophthalmitis in the age of outpatient intravitreal therapies and cataract surgeries: host-microbe interactions in intraocular infection. 
Prog. Retin. Eye Res., 31(4): 316-331. Talreja, D., Kaye, K.S., Yu, Fu-shin., Walia, S.K. and Kumar, A. 2014a. Pathogenicity of Ocular Isolates of Acinetobacter baumannii in a Mouse Model of Bacterial Endophthalmitis. IOVS, Volume 55, Number 4, pp. 23922402.

Talreja, D., Muraleedharan, C., Gunathilaka, G., Zhang, Y., Kaye, K.S., Walia, S.K. andKumar, A. 2014b. Virulence Properties of Multidrug Resistant
Ocular Isolates of Acinetobacter baumannii. Curr. Eye Res., 39(7): 695704.

Zalts, R., Neuberger, A., Hussein, K., RazPasteur, A., Geffen, Y., Mashiach, T. andFinkelstein, R. 2016. Treatment of Carbapenem-Resistant Acinetobacter baumannii Ventilator-Associated Pneumonia: Retrospective Comparison between Intravenous Colistin and Intravenous Ampicillin-Sulbactam. Am. J. Ther., 23: e78-e85.

\section{How to cite this article:}

Guilherme Barreto de Oliveira Ribeiro, Marcela de Almeida Costa Marques, Jean Phellipe Marques do Nascimento, Eliege Maria dos Santos, Roseana de Almeida Cunha Bastos, Eurípedes Alves da Silva Filho. 2017. Ocular Infection by Multidrug-Resistant Acinetobacter baumannii Causes Eyeball Evisceration - A Case Report. Int.J.Curr.Microbiol.App.Sci. 6(4): 1753-1758. doi: https://doi.org/10.20546/ijcmas.2017.604.210 